\title{
Investigating Parametric Variations of a Microstrip Antenna for Wifi Application
}

\author{
Ifeoma B. Asianuba, Remigious O. Okeke
}

\begin{abstract}
Antennas are fundamental component of wireless communication devices as such, there is an increased need for small, conformal, lightweight and efficient antennas to suit this wireless application. Antennas for Wifi applications can be embedded on the body of an equipment or a device. The characteristics of these antennas are unlike that of the conventional Aperture, linear and array antennas, which are though bulky and efficient but cannot be used for portable wireless devices. In this work therefore, the design requirement and simulation of a microstrip (patch) antenna for Wi-Fi application was carried out. The work investigates the parametric variations of a rectangular microstrip antenna in other to ascertain the implications of these variations in achieving the desired antenna performance. The method of solution was achieved with the use of CST software. It was shown in this work that; 1 . Antennas which possesses less VSWR is expected to have a good return loss. 2. A slight change in patch dimension brings about a significant change in the resonance frequency and subsequent increase in the bandwidth of the antenna. The designed antenna will find application in short range wireless communication devices operating at frequency of $2.4 \mathrm{GHz}$ with return loss less than $-10 \mathrm{~dB}$ and producing a gain above $5 \mathrm{~dB}$.
\end{abstract}

Keywords; antenna parameters, Microstrip patch, Wi-Fi application

\section{INTRODUCTION}

The society today depends so much on wireless technology since communication is a very important aspect of human life. There are several aspects of wireless communication, these include; commercial, entertainment and personal communication etc. (Mushfiqur, 2019). One essential component of wireless technology is the antenna. In radio engineering, an antenna sometimes referred to as an aerial, serves as a connection between electromagnetic waves that propagates through free space and the current which flows through a conducting surface. The latter could serve as a transmitting or a receiving device. Antennas are used in various devices such as wireless routers, televisions, blue tooth enabled devices, RFID tags, garage door openers, etc.

Some of the best antennas are the aperture, Yagi and other array antenna which are characterized due to its beam width to have improved gain with low manufacture and maintenance cost.

Ifeoma B. Asianuba. Department of Electrical/Electronic Engineering, University of Port Harcourt, Choba, Rivers State, Nigeria.

Remigious O. Okeke, Department of Electrical/Electronic Engineering, University of Port Harcourt, Choba, Rivers State, Nigeria
But one of the limitations of these antennas is that they are bulky and therefore are not suitable for personal communication devices as seen in mobile phones and cars. However, antennas of large dimension is not suitable for aerospace applications because such an antenna has to be light weight and conformal. Antennas that are needed for portable communication devices must be conformal, light weight, easy to manufacture, cheap and small depending on the size of device. Antennas that fit these characteristics are printed antennas. These antennas uses the same technology as printed circuit boards in their manufacturing process. They are mostly called planar antennas due to their plane nature. The characteristics of planar antenna is determined mainly by its dimensions in one plane (which is of two dimensions, the length and the width) and the size of the substrate. One popular planar antennas is the microstrip antennas. Microstrip patch antenna is made up of a radiating patch, a metal (usually copper), which rests on a part of the dielectric substrate and a ground plane, with the metal also on the other side (Patil and Dhanawade, 2019). This antenna is characterized by its feed type, operating frequency, patch dimension and dielectric constant. Dvakirubai et al 2012, Ramesh and Yip 2003, also investigated the types of feed for microstrip patch antenna.

\section{PROBLEM STATEMENT}

With the increase in wireless technology and mobile communication, small portable wireless devices which require low cost, compact, lightweight and effective performance has become a subject of great research interest. The demand for small and effective antennas for wireless communication has led to the investigation of the microstrip antennas. However, the microstrip antennas is not without limitations. One of its main limitations include narrow bandwidth and low directivity. The narrow bandwidth limitation is $15 \%$ to $50 \%$ that of commonly used antenna elements such as dipoles, arrays and apertures antennas. However, this paper investigates the parametric variations of a small size microstrip antenna to ascertain the dependence of the characteristics of the antenna parameters with respect to the radiation pattern so obtained. This is essential to obtain the required performance of the antenna for a specified application.

\section{BRIEF REVIEW OF RELATED WORK}

In Yuganand (2016), the design and simulation of a microstrip patch antenna for WLAN applications was implemented for a bandwidth of $5 \mathrm{GHz}-5.5 \mathrm{GHz}$. The range met the $5.2 \mathrm{GHz}$ WLAN communication standard. The antenna was designed using the high frequency simulation software (HFSS), which was also used to optimize the design properties. The 
frequency obtained on testing was approximately within the specified frequency band feasible for WLAN application.

In Akaniyene et al (2019), the design and simulation of a rectangular microstrip antenna array for improved gain performance was investigated. A major contribution of the work described the fact that; for any successful design of a microstrip patch antenna, the resonant frequency, the substrate and its required thickness must be specified. The HFSS was used in the simulation of the antenna. The feed method used was the microstrip line feed approach, where the length, width and inset feed point of the antenna was calculated to achieve impedance matching. Other feed method for the microstrip antenna include the coaxial cable and the aperture coupled feed type. In Karuna and Sridevi 2016, a comparative study was performed between the circular and rectangular microstrip antennas to investigate their design characteristics. Shanmugapniya R. 2015 showed that the microstrip antenna finds more application in wireless application.

\section{METHODOLOGY}

The first aspect of the design of a rectangular patch microstrip antenna is to specify the frequency at which the antenna is to resonate and the substrate to be used. The latter provides information of the dielectric constant of the substrate. These in turn provides a range of values for which the thickness of the substrate can be picked from. For the proposed antenna, the resonant frequency is $2.4 \mathrm{GHZ}$ and the substrate is the FR-4 Epoxy dielectric which has a thickness of $\mathrm{h}=0.8 \mathrm{~mm}$ and a dielectric constant $\epsilon \mathrm{r}=4.4$. To calculate the range in which the thickness of the dielectric substrate can be obtained, the free space wavelength $\lambda 0$ of the resonant frequency is used. The wavelength of $2.4415 \mathrm{GHz}$ is determined by;

$\lambda_{0}=\frac{c_{f}}{f_{r}}$

Where $\mathrm{C}_{f}=$ velocity of light $=3 \times 1011 \mathrm{~m} / \mathrm{s}$

$\mathrm{f}_{r}=$ resonant frequency of wave propagated by the antenna which is frequency at the center of the bandwidth $=2.4415 \mathrm{GHz}$

$\lambda_{0}=\frac{c_{f}}{f_{r}}=\frac{3 \times 10^{11} \mathrm{~m} / \mathrm{s}}{2.4415 \times 10^{9} \mathrm{~Hz}}=122.87 \mathrm{~mm}$

Thickness of substrate $t$, is valid for $0.003 \lambda_{0} \leq t \leq 0.05 \lambda_{0}$ at which the antenna can radiate efficiently. Therefore, the range of the substrate is $0.003 \lambda_{0} \leq \mathrm{t} \leq 0.05 \lambda_{0}=0.37 \mathrm{~mm} \leq \mathrm{t} \leq 6.14 \mathrm{~mm}$. The thickness of the proposed antenna is $0.8 \mathrm{~mm}$.

Step 1. Width of the Patch: For an efficient radiator, a practical width that leads to good radiation efficiency is

$$
\begin{aligned}
& \mathrm{W}=\frac{\mathrm{c}_{0}}{2 \mathrm{fr}} \sqrt{\frac{2}{\varepsilon_{r}+1}} \\
& =\frac{\mathrm{c}_{0}}{2 \mathrm{fr}} \sqrt{\frac{2}{4.4+1}}=\frac{c_{0}}{2 f r} \times 0.61=\frac{3 \times 10^{8} \times 0.61}{2 \times 2.4415 \times 10^{9}}
\end{aligned}
$$

$\mathrm{W}=0.03747 \mathrm{~m}=37.47 \mathrm{~mm}=37.5 \mathrm{~mm}$

Step 2. Effective Dielectric Constant, $\epsilon_{\text {reff: Radiation in a }}$ rectangular patch microstrip antenna is due to fringing effect. When the antenna is fed with respect to ground, electromagnetic waves get coupled from the patch to ground. For the part of the patch directly in contact with the substrate, the electromagnetic waves radiate from the patch through the substrate to ground. But when it comes to the edge of the microstrip antenna, electromagnetic fields passes through air first and then into the substrate before getting to the ground.

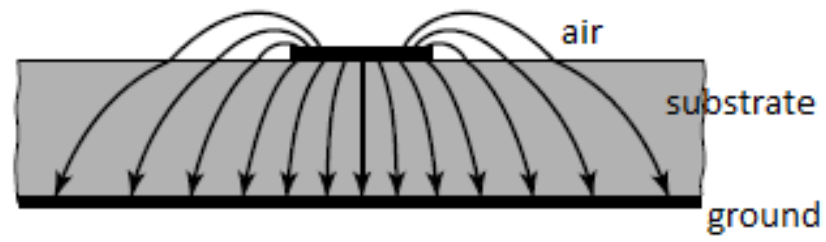

Figure 1. (a) Electric field lines

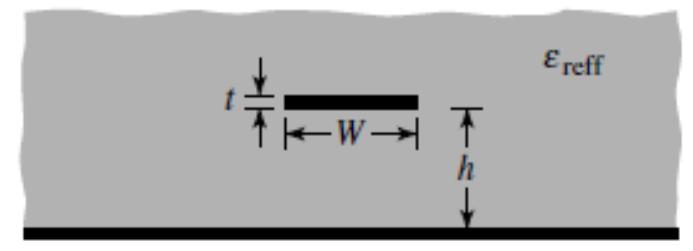

b. Effective dielectric constant

The fractional part of the electric field lines that passes through the air causes the antenna to radiate and this is fringing. For this reason part of the waves goes through air and the substrate with an effective dielectric constant $\epsilon_{\text {reff }}$ is introduced to handle the fringing and signal propagation through the line. The effective dielectric constant can be equated to that of a uniform dielectric material such that, the line has identical electrical characteristics particularly propagation constant with the actual line. For a line with air above the substrate, the effective dielectric constant has values in the range $1\left\langle\epsilon_{\text {reff }}\right\rangle \epsilon \mathrm{r}$. The effective dielectric constant is also a parameter that depends on frequency of the signal. Increase in the frequency of operation, brings about a corresponding concentration of the field lines in the substrate. The microstrip line is therefore seen as a homogeneous line with unity dielectric value, such that the effective dielectric constant approaches the value of the dielectric constant of the substrate.

The effective dielectric is given by

$\epsilon_{\text {reff }}=\frac{\epsilon_{r}+1}{2}+\frac{\in-1}{2}\left[1+12 \frac{h}{w}\right]^{-1 / 2}$

Dielectric constant of substrate, $\in_{\mathrm{r}}=4.4$

Height of substrate, $\mathrm{h}=1.2 \mathrm{~mm}$

Width of the patch $=37.5 \approx 38 \mathrm{~mm}$

$\epsilon_{\text {reff }}=\frac{4.4+1}{2}+\frac{4.4-1}{2}\left[1+12 \frac{1.2}{37.5}\right]^{-1 / 2}$

Step 3.Effective Length and Real Length of the Patch: Due to fringing effects, the dimension of the patch microstrip antenna appears larger than its physical dimensions and this is called the effective length and effective width of the patch respectively but its physical dimensions are the real length and width of the patch. 


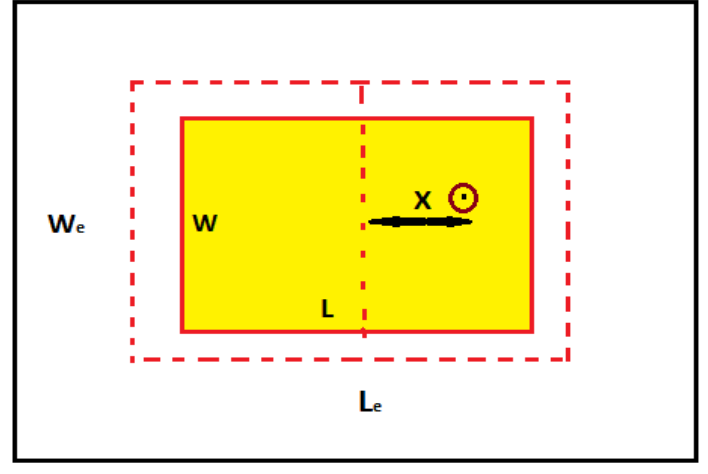

Figure 2. Effective length Le and real length L of the antenna The effective length of a microstrip patch antenna is given by

$$
L_{e f f}=\frac{c}{2 f r \sqrt{\varepsilon_{e f f}}}=30.2 \mathrm{~mm}
$$

$\mathrm{C}=3 \times 1011 \mathrm{~mm} / \mathrm{sec}, \mathrm{f}_{\mathrm{r}}=2.4415 \mathrm{GHz}, \epsilon_{\text {reff }}=4.14$

The incremental length of the patch $\Delta \mathrm{L}$ is

$$
\Delta L=0.412 h \frac{\left(\epsilon_{\text {reff }}+0.3\right)\left(\frac{w}{h}+0.264\right)}{\left(\epsilon_{\text {reff }}-0.258\right)\left(\frac{w}{h}+0.8\right)}=0.556 \mathrm{~mm}
$$

$$
\epsilon_{\text {reff }}=4.14, \mathrm{~W}=37.5 \mathrm{~mm}, \mathrm{~h}=1.2 \mathrm{~mm}
$$

Then the actual length $\mathrm{L}$ of the patch is found using $\mathrm{L}=\mathrm{L}_{\mathrm{eff}}-2 \Delta \mathrm{L}=30.2-2 \times 0.556=29.1 \approx 29 \mathrm{~mm}$.

Step 4. Dimension of the ground plane ( $\mathrm{Lg}$ and $\mathrm{Wg}$ ): The patch is placed on a substrate which in turn is placed on a ground plane. The dimensions of the substrate i.e., the length and width except the height, is the same as the ground plane. It is known that transmission line models are usually applied to infinite ground planes. Finite ground planes are applicable for practical considerations. It is possible to achieve similar results when the finite and infinite ground planes are in use. This can be obtained when the ground plane size is greater than the dimension of the patch by six times the size of the substrate (Balanis, 1997). It is therefore important to note that in microstrip designs, the ground plane dimensions can be expressed as:

$\mathrm{L}_{\mathrm{g}}=6 \mathrm{~h}+\mathrm{L}=6(1.2)+29.1=36.3 \approx 37 \mathrm{~mm}$

$\mathrm{W}_{\mathrm{g}}=6 \mathrm{~h}+\mathrm{W}=6(1.2)+37.5=44.7 \approx 45 \mathrm{~mm}$

Step 5. Feeding of the microstrip antenna

The proposed microstrip antenna is fed using a coaxial line which is fed through the bottom of the antenna. The coaxial line has an inner conductor which is attached to the radiation patch and so is inserted through the ground plane and the substrate of the antenna. In between the two conductors is a dielectric substrate. The coaxial probe feed is easy to fabricate and match. The parts of the coaxial feed line are cylindrical. By specification, an SMA connector usually have Teflon as the dielectric substrate which has dielectric constant of 2.1.

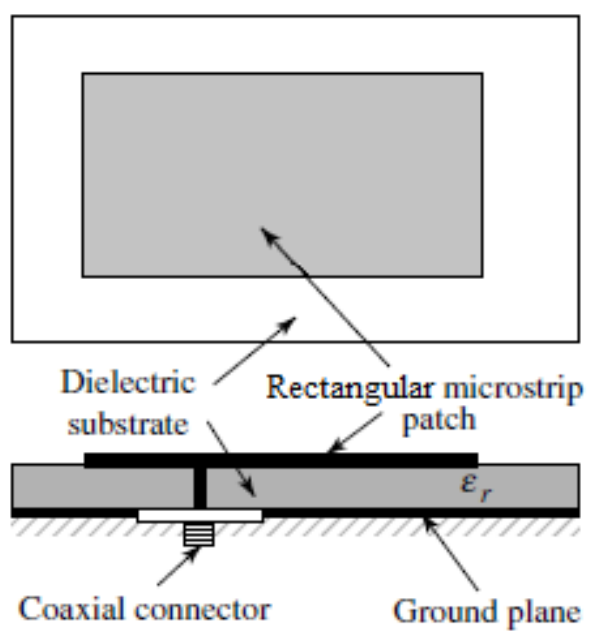

Figure 3. A rectangular microstrip using a coaxial line feed

The proposed antenna has an input impedance of $50 \Omega$. The input impedance of the coaxial line needs to match the impedance of the microstrip antenna. This depends on the diameters of the inner conductor and the dielectric substrate. For there to be an impedance matching the diameter of the inner conductor must satisfy the relationship

$Z_{0}=\frac{138}{\sqrt{\epsilon_{r}}} \log _{10} \frac{D_{d}}{D_{c}}$

Where $Z_{0}$ is the input impedance $=50 \Omega$

$\epsilon \mathrm{r}$ is the dielectric constant of the substrate $=2.1$

Dd is the diameter of the dielectric coat

Dc is the diameter of the pin conductor

There are various pairs of values for the diameter of the dielectric coat and the pin conductor that will give an input impedance of $50 \Omega$. But usually the diameter of the inner conductor suitable for a coaxial-fed microstrip antenna is $1.0 \mathrm{~mm}$. Respectively, this will give the diameter of the Teflon dielectric substrate as $3.4 \mathrm{~mm}$.

Calculating the feed point location

In the fundamental mode of a microstrip patch antenna, the length of the patch is approximately $\lambda / 2$. Looking at the current point of view, $\lambda / 2$ means that there are openings at the two extremes of the length of the patch (at the width). So along the width, current would be zero and maximum at the middle length of the patch and comes back to zero at the other width of the patch. This is known as a half wavelength. For voltage distribution, it will be different from that of current. At one side of the width, the voltage is maximum, at the middle length of the patch the voltage is zero and at the other width of the patch the voltage is negative maximum. With this the impedance distribution of the antenna can be understood. At the width of the patch where the current is zero and the voltage is maximum, the impedance which is voltage divided by current, will be maximum. At the middle length of the antenna where voltage is zero and current is maximum, the impedance will be zero. From the middle length of the antenna to the other width, the voltage starts reducing to negative values and so the impedance will be negative. 


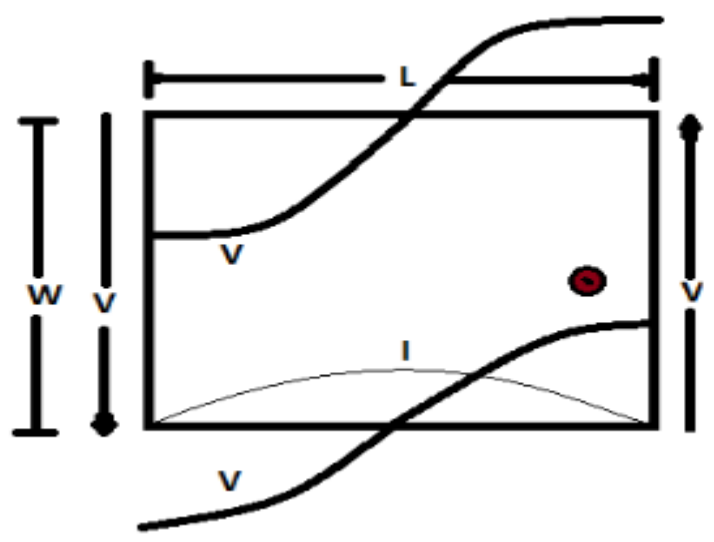

Figure 4. Current and voltage distribution of a rectangular microstrip antenna

In other to feed the antenna, it is necessary to find the point where the impedance will be $50 \Omega$, the feed point has to be at the part of the antenna where the voltage is positive and would be closer to the point where the impedance is zero. The value of this point $\mathrm{x}$ is between $\mathrm{L} / 4$ to $\mathrm{L} / 6$. Points closer and equal to the $\mathrm{L} / 6$ mark is used if a narrow bandwidth is desired and points closer or equal the $\mathrm{L} / 4$ mark is used if a wider bandwidth is desired. Therefore, for the $\mathrm{x}$ coordinate point

$\mathrm{Y}=\{\mathrm{y}: \mathrm{L} / 6 \leq \mathrm{y} \geq \mathrm{L} / 4\}=\{\mathrm{y}: 7.275 \leq \mathrm{y} \geq 4.85\}$

Since any point can be picked, for this project, $6.8 \mathrm{~mm}$ was used. For the y coordinate point, the middle is the point where it is fed.

$\mathrm{X}=37.5 / 2=18.75 \mathrm{~mm}$

Therefore, the inset feed point coordinate is

$\mathrm{X}, \mathrm{Y}=18.75 \mathrm{~mm}, 6.8 \mathrm{~mm}$

Therefore, from the calculations the basic parameters for the modeling of the antenna on the software are shown in table 3.2

Table 3.2 Calculated Antenna Parameters

\begin{tabular}{|l|l|l|}
\hline & Antenna Parameters & Values \\
\hline 1 & Resonance Frequency & $2.4 \mathrm{GHz}$ \\
\hline 2 & Height of Substrate & $1.2 \mathrm{~mm}$ \\
\hline 3 & Width of Patch & $38 \mathrm{~mm}$ \\
\hline 4 & Length of Patch & $29 \mathrm{~mm}$ \\
\hline 5 & Width of substrate/ground plane & $45 \mathrm{~mm}$ \\
\hline 6 & Length of substrate/ground plane & $37 \mathrm{~mm}$ \\
\hline 7 & Thickness of metal sheet & $0.1 \mathrm{~mm}$ \\
\hline 8 & Coaxial line feed point $(\mathrm{x}, \mathrm{y})$ & $18.75 \mathrm{~mm}, 6.8 \mathrm{~mm}$ \\
\hline 9 & Diameter of dielectric coat & $3.4 \mathrm{~mm}$ \\
\hline 10 & Diameter of pin conductor & $1.0 \mathrm{~mm}$ \\
\hline
\end{tabular}

These are the important parameters used for the design of the microstrip antenna with the aid of CST design software.

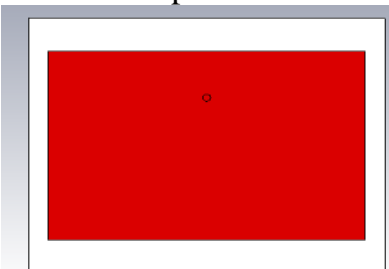

(a)

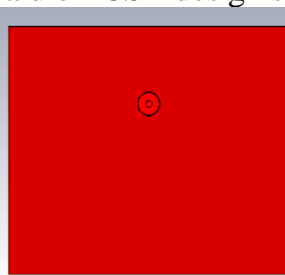

(b)

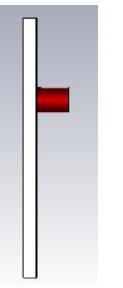

(c)
Figure 5 Model of the antenna from CST software (a) Front view showing the patch and the substrate and the coaxial feed point (b) Back view showing the ground and the coaxial feed and (c) the Right side

\section{PERFORMANCE PARAMETERS OF MICROSTRIP ANTENNA.}

The performance of an antenna is described by the parameters of that antenna. These parameters include; the radiation pattern, the gain, the directivity, bandwidth, return loss and voltage standing wave ratio.

\section{RESULT AND DISCUSSION}

The software used to model and simulate the Microstrip patch antenna is the Computer Simulation Technology (CST) Studio Suite. The latter is a high-performance 3D electromagnetic analysis software package for designing, analyzing and optimizing electromagnetic (EM) components and systems.

\section{SIMULATION RESULT OF THE DESIGNED ANTENNA}

THE RETURN LOSS (REFLECTION COEFFICIENT)

Return loss is a parameter used to describe the power reflected by an antenna which is as a result of mismatch of the transmission line and the antenna (Derren, 2014). Return loss is the negative equivalence of the reflection coefficient. Table 1 is a table showing the relationship between return loss, VSWR and its interpretation.

Table 1 Return Loss and VSWR (Antenna Test lab)

\begin{tabular}{|l|l|l|}
\hline $\begin{array}{l}\text { Return } \\
\text { Loss in } \mathrm{dB}\end{array}$ & Description & $\begin{array}{l}\text { VSWR } \\
\text { Number }\end{array}$ \\
\hline $0 \mathrm{Db}$ & $\begin{array}{l}100 \% \text { reflection, no power into } \\
\text { the antenna, all reflected back }\end{array}$ & Infinite \\
\hline $1 \mathrm{~dB}$ & $\begin{array}{l}80 \% \text { reflection, 20\% power } \\
\text { into the antenna }\end{array}$ & 17 \\
\hline $2 \mathrm{~dB}$ & $\begin{array}{l}63 \% \text { reflection, 37\% power } \\
\text { into the antenna }\end{array}$ & 9 \\
\hline $3 \mathrm{~dB}$ & $\begin{array}{l}50 \% \text { reflection, 50\% power } \\
\text { into the antenna }\end{array}$ & 6 \\
\hline $5 \mathrm{~dB}$ & $\begin{array}{l}32 \% \text { reflection, 68\% power } \\
\text { into the antenna }\end{array}$ & 3.5 \\
\hline $6 \mathrm{~dB}$ & $\begin{array}{l}25 \% \text { reflection, 75\% power } \\
\text { into the antenna }\end{array}$ & 3 \\
\hline $8 \mathrm{~dB}$ & $\begin{array}{l}16 \% \text { reflection, 84\% power } \\
\text { into the antenna }\end{array}$ & 2.3 \\
\hline $10 \mathrm{~dB}$ & $\begin{array}{l}10 \mathrm{~dB}(10 \% \text { reflection, 90\% } \\
\text { power into the antenna) }\end{array}$ & 2 \\
\hline $15 \mathrm{~dB}$ & $\begin{array}{l}15 \mathrm{~dB}(3 \% \text { reflection, 97\% } \\
\text { power into the antenna) }\end{array}$ & 1.4 \\
\hline $20 \mathrm{~dB}$ & $\begin{array}{l}20 \mathrm{~dB}(1 \% \text { reflection, 99\% } \\
\text { power into the antenna) }\end{array}$ & 1.2 \\
\hline
\end{tabular}

From the reflection coefficient graph as shown in figure 6, it shows that the antenna resonates at $2.341 \mathrm{GHz}$ frequency having an error of $4.07 \%$ since it was designed for $2.4415 \mathrm{GHz}$. The reflection coefficient graph also shows the return loss or $\mathrm{S}_{11}$ parameter as $-12.69 \mathrm{~dB}$, and according to table 1 this is very good since this shows that more than $90 \%$ of power transmitted into the antenna is radiated out. 


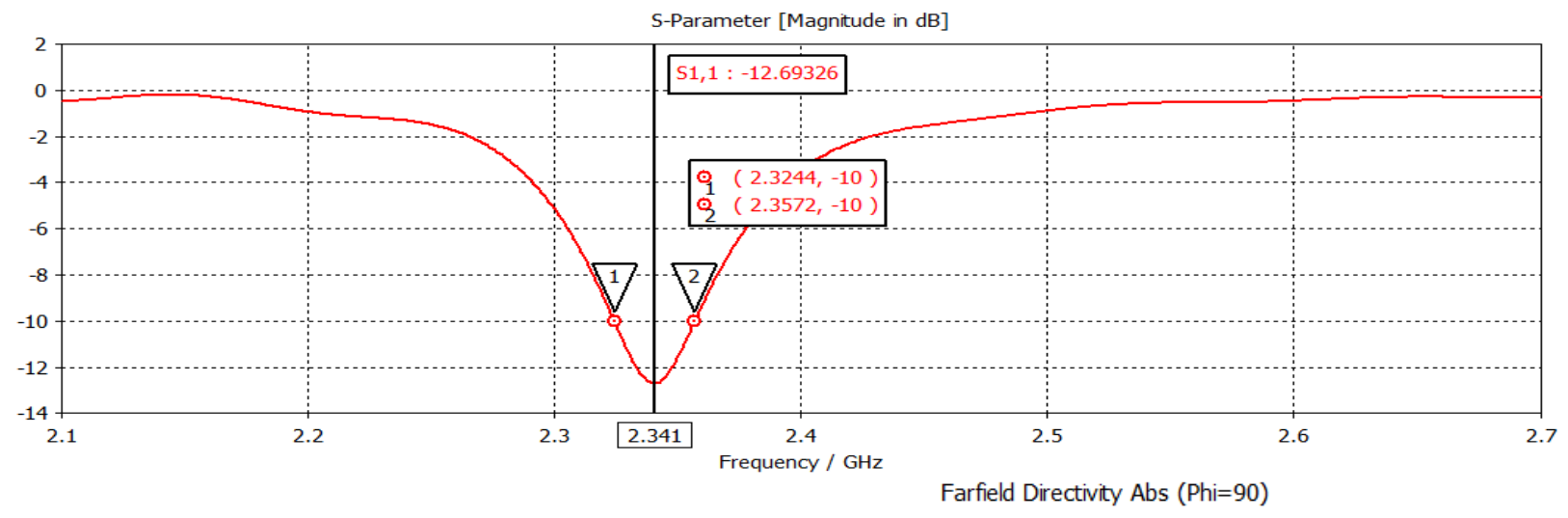

Fig. 6. Return loss plot of the simulated antenna

\section{BANDWIDTH}

Bandwidth is the capacity of a wired or wireless network communications link to transmit the maximum amount of data from one point over a network in a given amount of time. The bandwidth which is measured on the $10 \mathrm{~dB}$ line of the return loss graph shows the bandwidth of the antenna.

The bandwidth here is the difference between the two points as indicated in figure 6 , which is $2.3572-2.3244=32.8 \mathrm{MHz}$. This is a very small bandwidth. It confirms the major drawback/limitation of the microstrip antenna.

VSWR

The Voltage standing wave ratio is a parameter used to describe the return loss of an antenna.it is a ratio which describes the presence of forward and reflected radio waves existing simultaneously in a transmission line.

From the VSWR plot, it shows that at the resonant frequency of $2.341 \mathrm{GHz}$, the voltage standing wave ratio is 1.60 which corresponds to the value gotten for the return loss plot of table 1 .

\section{RADIATION PATTERN}

Figure 8 shows the radiation pattern of the simulated antenna. The figures show the radiation pattern (in the theta phase angle) and the radiation pattern in the phi phase angle.

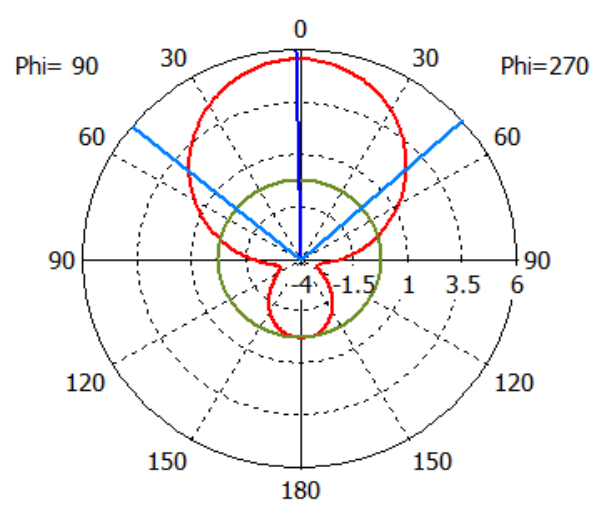

Theta / Degree vs. dBi

\section{Frequency $=2.4$}

Main lobe magnitude $=5.58 \mathrm{dBi}$

Main lobe direction $=1.0 \mathrm{deg}$.

Angular width $(3 \mathrm{~dB})=99.1 \mathrm{deg}$.

Side lobe level $=-5.8 \mathrm{~dB}$

Figure 8: Far field directivity in the theta phase angle

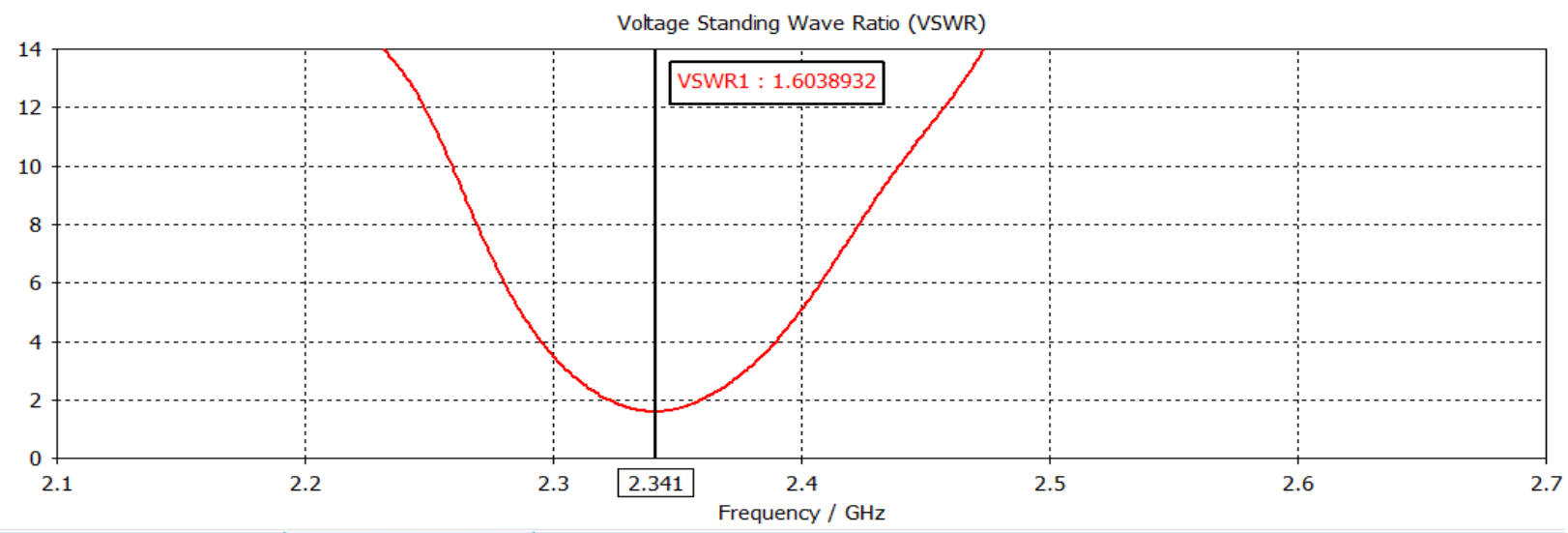

The main lobe magnitude is $5.58 \mathrm{dBi}$. This is the directivity of

Figure 7 VSWR of the simulated antenna the antenna. 


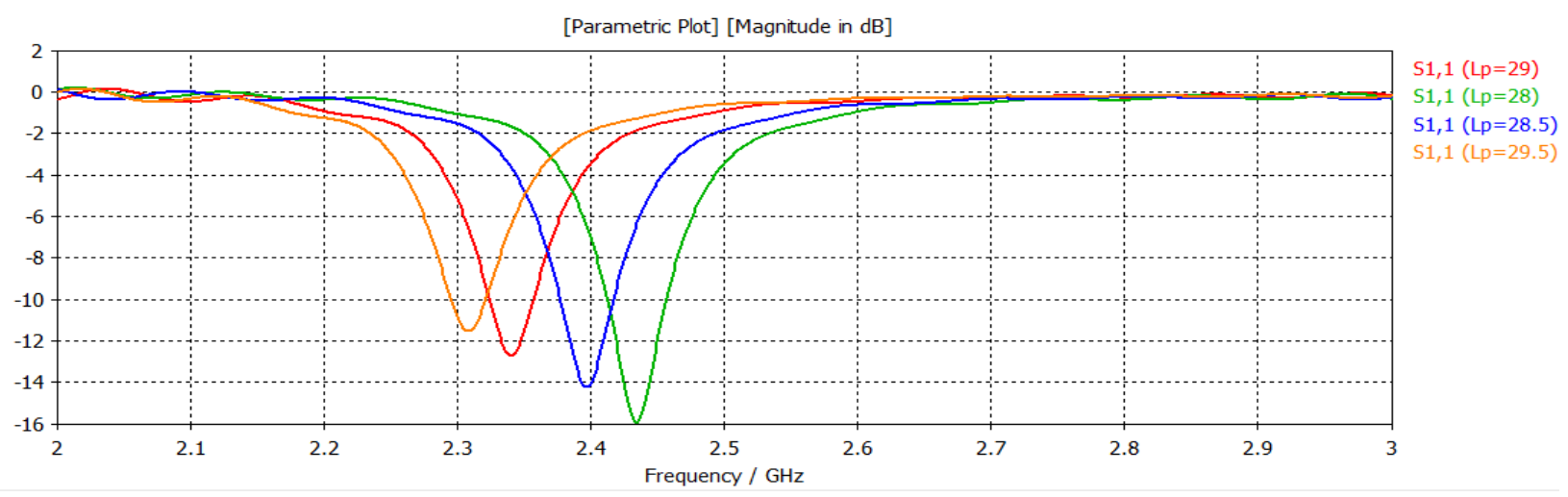

Figure 9. S-Parameter graphs showing variation in patch length

\section{PARAMETRIC STUDY OF THE RECTANGULAR MICROSTRIP ANTENNA}

In the course of the work, research on the effect of various parametric variations on the performance of a rectangular microstrip antennas was carried out with the following results.

\section{Length of the Patch}

To effectively study the parametric effect of the patch length, simulation was carried out for patch lengths of 28.5, 29, 29.5, and $30 \mathrm{~mm}$. The results are shown in the figures below

Return Loss, Resonating Frequency and Bandwidth

The S-Parameter graph as shown in figure 9 shows the return loss, the resonance frequency and the bandwidth at the different lengths of patch. For the return loss, as the patch lengths increases the return loss decreases. It decreased from $14.16 \mathrm{~dB}$ to $10.63 \mathrm{~dB}$ as the length increased from $28.5 \mathrm{~mm}$ to $30 \mathrm{~mm}$.

For its resonance frequency, as the patch length increases the resonance frequency decreases. A resonance frequency of $2.397 \mathrm{GHz}$ generated with a patch length of $28.5 \mathrm{~mm}$, decreases as the patch length increases, such that, the patch length now becomes $30 \mathrm{~mm}$, for a resonance frequency of $2.277 \mathrm{GHz}$. It can also be said that with a small change in the patch length, there is a significant change in the resonance frequency. Therefore, to adjust the frequency at which the antenna is resonating, the length of patch should be adjusted with a prior information on its level of dependence to achieve the desired frequency.
The S-Parameter (return loss) graph is also used to calculate the bandwidth of the antenna by subtracting the lower limit from the upper limit at the $10 \mathrm{~dB}$ line. The values of the frequency at the upper and lower limit are shown in the graph. As can be seen from the graph, the width at the $10 \mathrm{~dB}$ line of the graph decreases as the patch length increases.

\section{VSWR}

Figure 10 shows the variation in the voltage standing wave ratio of the antenna as the length of the patch is increased with other parameters left constant. It can also be seen that as the length of the patch increases, the VSWR of the antenna also increases and as such more power is reflected back into the source. For the radiation pattern, there is no considerable change when the patch length increases or decreases

\section{WIDTH OF PATCH}

To effectively study the parametric effect of the patch width, simulation was carried out for patch widths of 36, 38, 40 and $42 \mathrm{~mm}$. The results are shown in the figures 11

The return loss graph as shown in figure 6 shows; that an increase in the patch width increases the return loss of the antenna, shifts the resonance frequency to the left thereby reducing it and increases the bandwidth. This is because as the width increases, ereff also increases and when ereff increases frequency decreases. As well, a larger width will give rise to larger fringing fields and larger fringing fields will mean more losses or radiation return loss.

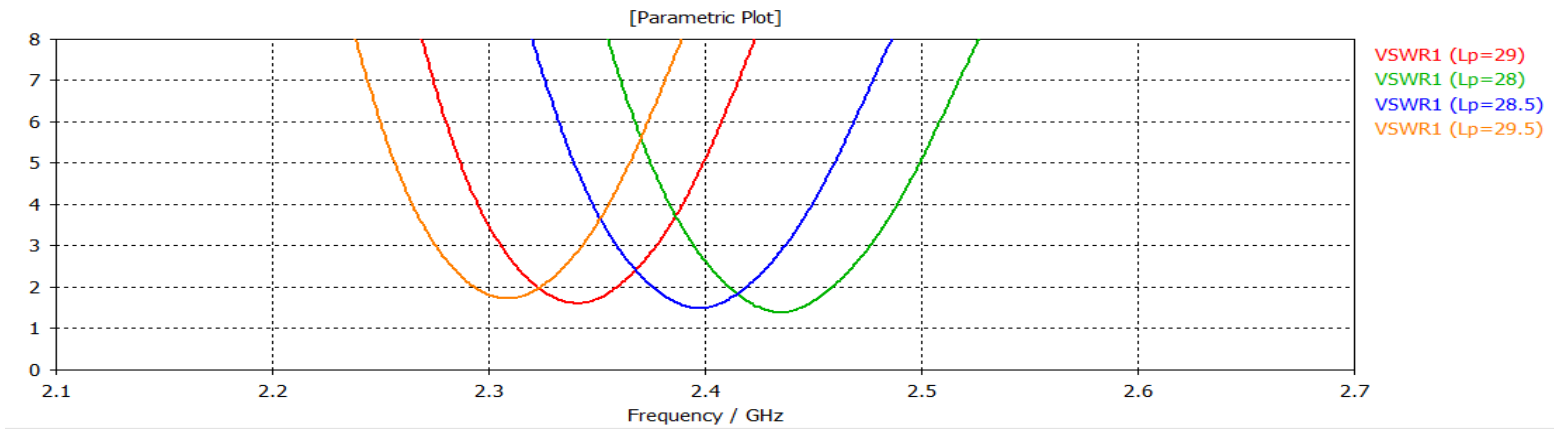

Figure 10 VSWR graph showing variation in patch length 


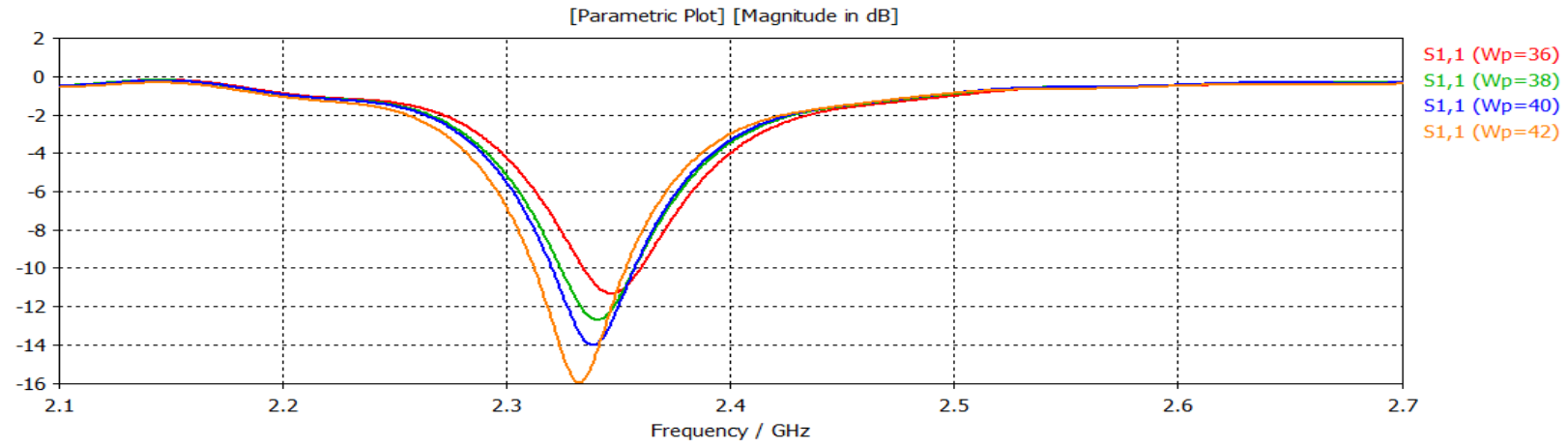

14), bandwidth as well as the return loss.

Figure $11 \mathrm{~S}$-Parameter graphs showing variation in patch width

\section{VSWR}

Figure 12 shows the variation in the voltage standing wave ratio of the antenna as the width of the patch is increased with other parameters left constant. It can be seen that as the width of the patch increases, the VSWR of the antenna also decreases and as such more power is radiated by the antenna. For the radiation pattern, there is no considerable change when the patch length increases or decreases.

Figure 12 VSWR graphs showing variation in patch width

\section{VSWR}

The VSWR graphs in figure 14 shows that as the substrate height increases, this will lead to an increase in the voltage standing wave ratio of the antenna.

\section{CONCLUSION}

The design and simulation of the rectangular patch antenna was successful using the CST suite 2013 software. The parametric study was carried out using the physical dimensions (length, width and height), and size of substrate of the microstrip antenna. The results obtained showed the [Parametric Plot]

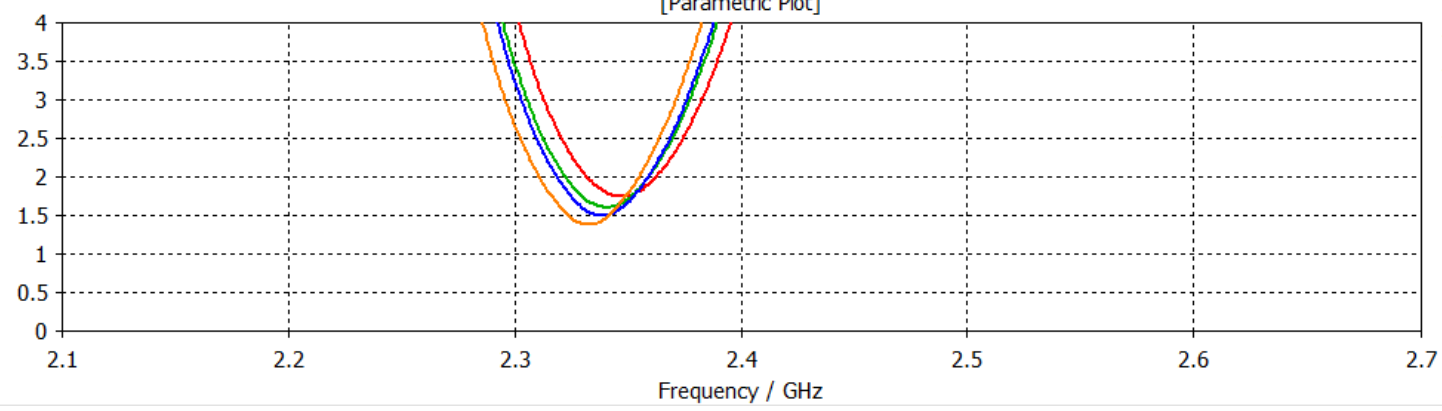

Figure 12 VSWR graphs showing variation in patch width

\section{Height of Substrate (Substrate thickness)}

To effectively study the parametric effect of the substrate thickness, simulation was carried out for substrate thicknesses of $0.8,1.0,1.2$, and $1.4 \mathrm{~mm}$. The results are shown in the figure 13 below

Return loss, Resonating frequency and Bandwidth If substrate thickness is increased, fringing fields will increase, this implies that the total length of the patch will increase and that will lead to reduced resonance frequency (figures 13 and

dependence of the physical dimension of the antenna on its performance characteristics. It was shown that; 1 . Antennas which possesses less VSWR is expected to have a good return loss. 2. A slight change in patch dimension brings about a significant change in the resonance frequency and subsequent increase in the bandwidth of the antenna. However the microstrip antenna in general is suitable for portable communication devices used for wi-fi applications.

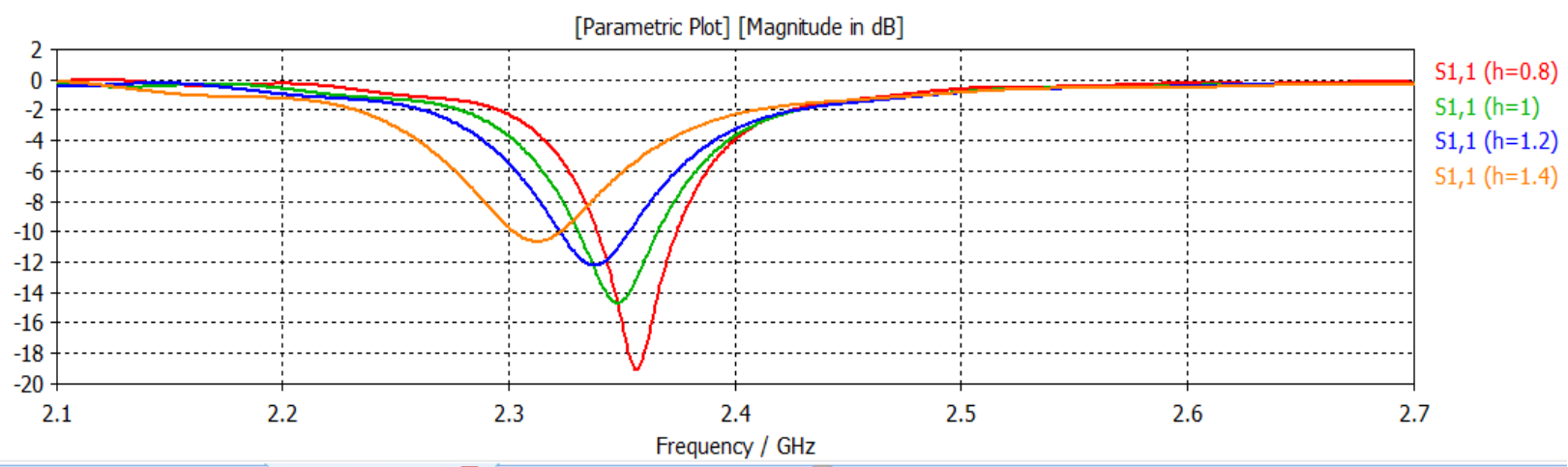


Investigating Parametric Variations of a Microstrip Antenna for Wifi Application

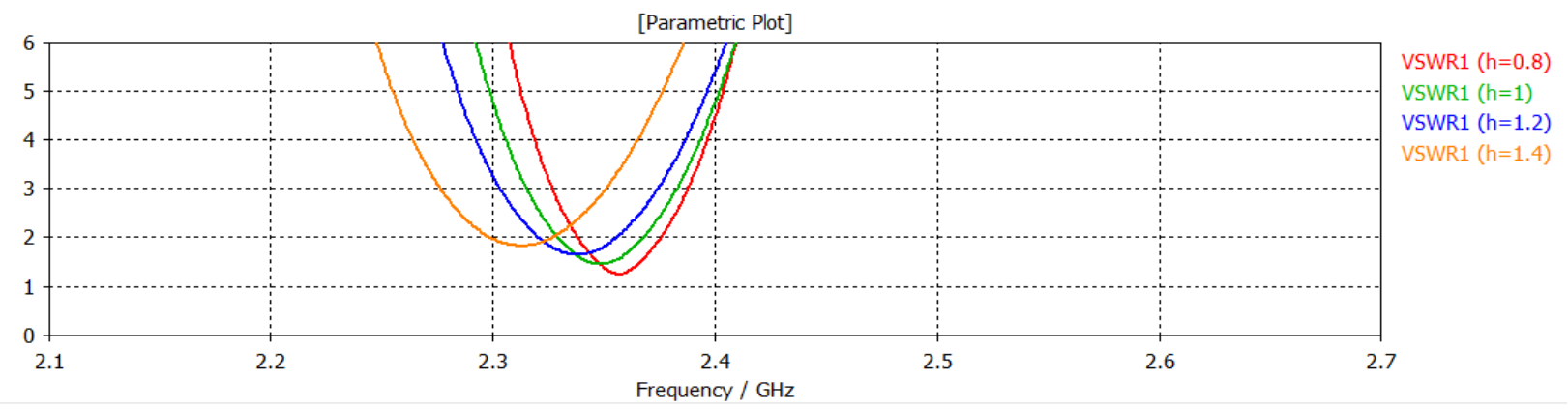

Figure 14 VSWR graphs showing variation in substrate height

\section{REFERENCE}

[1] Akaninyene B. O, Gabriel A. Igwue, K. and Udofia M 2019. Design and Simulation of Rectangular Microstrip Antenna Arrays for Improved Gain Performance. International Journal of Networks and Communications; article.sapub.org/10.5923.j.ijnc.20190902.02.html

[2] Antenna Test Lab. Return Loss and VSWR, antennatestlab.com

[3] Derren O, 2014. Back to Basics in Microwave Systems: Return Loss and VSWR, retrieved from https://www.commscope.com/ October 2019.

[4] Dvakirubai G. D et al 2012. Design and comparative study of pin fed and line feed microstrip patch antenna for $\mathrm{X}$ band application. International Journal of Applied information system Vol 1 issue $4 \mathrm{pp}$. 21-25.

[5] Karuna K. and Sridevi P.V. 2016. Design and Analysis of microstrip array antenna using CST software. International Journal of Engineering science and computing, Vol 6 issue 5, pp. 5977-5982.

[6] Mushfiqur 2019, The Importance of Wireless Communication in Developing Countries, retrieved from www.techetron.com.

[7] Patil S. A. and Dhanawade P. C. 2019; Microstrip Antenna and Their Applications, retrieved from https://electronicsforu.com/technology-trends/microstrip-antenna-a pplications

[8]Ramesh M and Yip K. B. 2003. Design formula for Inset fed microstrip patch Antenna. Journal of Microwave and Optoelectronics, Vol 3 issue 3 pp 121-129.

[9] Shanmugapniya R. 2015. Design and Analysis of Rectangular Microstrip patch Antenna using Inset fed Technique for Wireless application. International Journal of Innovative Research in Science Engineering and Technology Vol 4 issue 4, pp 34-40.

[10] Yuganand, H. J. 2016, Design and Simulation of Single Band Rectangular Microstrip Patch Antenna for WLAN Application; International Journal of Modern Communication Technologies \& Research (IJMCTR), media.neliti.com/media/publications 